Vol 11, Issue 10, 2018

\title{
MECHANISTIC ROLE OF VARUNA (CRATAEVA NURVALA) EXTRACT ON THYROID GLAND AND ITS HISTOLOGY THROUGH IODOTHYRONINE DEIODINASES
}

\author{
ARSHVIR KAUR ${ }^{1}$, SANTOSH KUMAR VERMA ${ }^{1,2}$ \\ ${ }^{1}$ Department of Pharmacology, CT Institute of Pharmaceutical Sciences, Shahpur, Jalandhar, Punjab, India. ${ }^{2}$ Department of Pharmacology, \\ Faculty of Pharmaceutical Sciences, Motherhood University, Roorkee, Haridwar, Uttarakhand, India. Email: archie.dhwal@gmail.com
}

Received: 11 May 2018, Revised and Accepted: 20 June 2018

\section{ABSTRACT}

Objective: Crataeva nurvala (CN) is used for its therapeutic effects, but its effect on the thyroid gland in euthyroid conditions and mechanism behind its thyrotropic activity in hypothyroidism is still not explored. This study screened the pharmacological effect of the ethanolic extract of the bark of CN on thyroid hormones, free and total thyroxine ( $\mathrm{FT}_{4}$ and $\left.\mathrm{T}_{4}\right)$, triiodothyronine $\left(\mathrm{T}_{3}\right)$, thyroid-stimulating hormone (TSH) levels, and thyroid histology in normal Swiss albino female mice.

Methods: Eighteen animals of 28-33 g were segregated into three groups: Group I treated with vehicle (NOR+VEH), Group II administered CN $400 \mathrm{mg} / \mathrm{kg}$ (NOR+CN 400), and Group III given CN $600 \mathrm{mg} / \mathrm{kg}$ (NOR+CN 600), for 15 days, per os (p.o.). The variation in the $\mathrm{T}_{4} \mathrm{FT}_{4}, \mathrm{~T}_{3}$, and TSH levels was recorded using ELISA, $24 \mathrm{~h}$ after the last dose, and $\mathrm{T}_{3} / \mathrm{T}_{4}$ ratio thus calculated along with the histopathological studies of the thyroid gland.

Results: The findings were presented as mean \pm standard error of the mean, using one-way ANOVA, followed by Dunnett's post-tests to compare all columns with the control. NOR+CN 600 has shown thyroid protective effect through retaining euthyroid profile, normal $\mathrm{T}_{3} / \mathrm{T}_{4}$ ratio, and near-normal histology. However, NOR+CN 400 had shown the significant decline in $\mathrm{T}_{3} / \mathrm{T}_{4}$ ratio and pathological changes in thyroid histology, in comparison with the control and NOR+VEH group.

Conclusion: The higher dose of $\mathrm{CN}$ was found to sustain the euthyroid levels through retention of iodothyronine deiodinases activity, facilitating the peripheral conversion of $\mathrm{T}_{4}$ to $\mathrm{T}_{3}$, and in retaining normal histoarchitecture of the thyroid gland in contrary to a lower dose.

Keywords: Varuna, Thyroxine, Triiodothyronine, Iodothyronine deiodinase, Euthyroid.

(C) 2018 The Authors. Published by Innovare Academic Sciences Pvt Ltd. This is an open access article under the CC BY license (http://creativecommons. org/licenses/by/4. 0/) DOI: http://dx.doi.org/10.22159/ajpcr.2018.v11i10.27245

\section{INTRODUCTION}

Crataeva nurvala (CN) commonly known as Varuna is reported to possess various pharmacological activities such as analgesic, anthelmintic, antiarthritic, antibacterial, anticancer, antidiabetic, antidiarrheal, antifertility, anti-hemolytic, anti-snake venom, antiinflammatory, antimycotic, antioxidant, antiurolithiatic, cardioprotective, hepatoprotective, nephroprotective, neuroprotective, and antimalarial activities. It is also found to be effective in treating urinary tract infections as evident from various in vivo-in vitro studies in disease conditions [1-6].

Furthermore, Varuna is a part of various polyherbal Ayurvedic, Siddha, and commercially manufactured formulations, used for certain pharmacological actions such as Asmarihara kasaya (antihypertriglyceridemia and hepatoprotective), Pashanabhedadi Ghrita (antinephrolithiatic and antioxidant), Vedikara silasathu parpam and Nerunjil kudineer (anti-inflammatory), Himplasia (Himalaya Herbal Healthcare, Bengaluru) used for Benign Prostatic Hyperplasia, and Neeri (Aimil Pharmaceuticals India Ltd., New Delhi) as nephroprotective [7-11].

In a recent study, the bark extract of $\mathrm{CN}(\mathrm{CN} 600 \mathrm{mg} / \mathrm{kg})$ had shown to possess significant thyroid stimulant activity when compared with the standard therapy i.e. levothyroxine in propylthiouracil (PTU) induced hypothyroidism. It showed significant reduction in cholesterol levels and improved thyroid hormone levels, proving its beneficial role in the treatment of hypothyroidism and associated hypercholesterolemia. However, the lower dose ( $\mathrm{CN} 400 \mathrm{mg} / \mathrm{kg}$ ), despite raising $\mathrm{T}_{4}$ levels, in an erratic manner, raised thyroid stimulating hormone (TSH) also, for which mechanism was not clear [12]. Moreover, its effect in the euthyroid state, when used for other ailments in the form of polyherbal preparations or certain extracts, is still unexplored. For estimating the mechanism, an additional diagnosis like $\mathrm{T}_{3}$ is also required, which was not estimated in previous studies, needed to be estimated.

Hence, this study was framed to evaluate the per se effect of $\mathrm{CN}$ on thyroid hormone levels, thyroid histology, and its mechanism through estimating thyroid hormones, i.e. $\mathrm{T}_{4}$ (total and free) and $\mathrm{T}_{3}$ levels, $\mathrm{TSH}$, $\mathrm{T}_{3} / \mathrm{T}_{4}$ ratio, and histopathological studies in the normal healthy female mice.

\section{METHODS}

\section{Animals}

Swiss Albino healthy female mice, having age around 3-5 months and body weight 28-33 g, were purchased from "Panacea Biotec Ltd., Lalru (140501), India." Animals were kept in cages made of polypropylene, under specified temperature conditions such as $25 \pm 2{ }^{\circ} \mathrm{C}$ and relative humidity $30-70 \%$ with the maintenance of 12 -h night and 12 -h day cycle. Animals were nourished with standard pellets of food purchased from "Shree Jagdambey Feed Industries" situated in Moga (Punjab), and potable water was supplied on a free basis. The prior approval for the conduct of the study was taken from the Institutional Animal Ethics Committee (IAEC) under Protocol no.: IAEC-CTIPS/2015/VII/0042 (PCL-M) as per the guidelines of the Committee for the Purpose of Control and Supervision on Experiments on Animals (CPCSEA), New Delhi.

\section{Procurement of plant material: CN}

The CN bark ( $3.5 \mathrm{~kg}$ ) was purchased from Herbal Health Research Consortium Pvt., Ltd. (HHRC), Amritsar, from Lot No. VRN-024 along with Certificate of Analysis (COA) whose A. R. No. was 06/2015/ 
IH/086, in consistency with Q.S.I.M.P.; 10: 106-108. Certified purchase voucher with voucher no. HHRC/RT/0416/15-16, along with the bark sample, was deposited to the Department of Pharmacology, CT Institute of Pharmaceutical Sciences, for further reference.

\section{Preparation of extract}

The $\mathrm{CN}$ bark extract was prepared through triple maceration strategy [13]. $3.5 \mathrm{~kg}$ of CN bark was dried in shade and rendered free of dust. The size reduction was achieved, first by manual crushing, thereafter undergoing an electrical grinding (sieve size \#16). Ethanol ( $1 \mathrm{~kg}$ in $3 \mathrm{~L}$ ) was used as a solvent to macerate the coarse powder at room temperature with periodic shaking. The straining was done by layer muslin fabric in 2 folds, and the marc pressing was done to extricate the solvent. The individual filtrates were obtained, combined, and filtered through Whatman No. 1 paper. This procedure was rehearsed every $3^{\text {rd }}$ day to achieve triple maceration. All the filtrates were stored in light-resistant bottles. The recovery of the solvent was done under vacuum at $37^{\circ} \mathrm{C}$ and allowed to concentrate to get dark semisolid mass. The yield obtained was $1.37 \%$.

Chosen amount of extract, i.e. $400 \mathrm{mg} / \mathrm{kg}$ and $600 \mathrm{mg} / \mathrm{kg}$ was used, based on available literature, scientific evidence for its neurological, hepatic and renal safety, therapeutic efficacy, and thyrotropic activity in PTU-induced hypothyroidism to evaluate its mechanism [12]. For administration, suspension using Gum Acacia (1\%) and preserved at $2-8^{\circ} \mathrm{C}$ in light-resistant bottle [14-17].

\section{Preliminary phytochemical screening}

The qualitative phytochemical estimation of CN ethanolic extract was conducted using tests such as Keller-Killiani test, sodium hydroxide test, lead acetate test, Salkowski test, Lieberman's test, silver nitrate test, and frothing test. Every reagent taken was of analytical grade.

\section{Experimental procedure}

Mice of 28-33 g were segregated into three groups, i.e. Group I, vehicle treated, and Groups II and III, administered with CN $400 \mathrm{mg} / \mathrm{kg} \mathrm{BW}$ and $\mathrm{CN} 600 \mathrm{mg} / \mathrm{kg}$ BW for 15 days, orally. The variation in the $\mathrm{T}_{4}, \mathrm{FT}_{4}$, T3, and TSH was analyzed on the $15^{\text {th }}$ day. Dosage administration was done every day between 9.00 am and 10.00 am to avoid any circadian alteration.

\section{Serum preparation}

The blood samples were ensured to be collected after $24 \mathrm{~h}$ of the last dose administered, through retro-orbital puncture method. The blood specimen was permitted to get coagulate, and centrifugation for 20 min was carried out thereafter to obtain serum. The serum, thus, obtained was preserved at $-2^{\circ} \mathrm{C}--8^{\circ} \mathrm{C}$ until examined for biochemical examinations.

\section{Biochemical parameter estimation in serum}

Serum $\mathrm{T}_{4}, \mathrm{FT}_{4}, \mathrm{~T}_{3}$, and TSH were estimated by ELISA as per the instructions given in protocol by ERBA Lachema s.r.o., Czech Republic, and Calbiotech Inc., Austin, CA, at end of the study.

\section{Histological studies}

The histology of thyroid gland was performed using hematoxylin and eosin staining method [18]. The thyroid glands were removed, rinsed, and immersed in formaldehyde solution. The section was first deparaffinized, and slide was flamed over the burner and repeatedly agitated in xylene for 3-5 min. The section is first hydrated with water and then in decreasing concentration of alcohol, i.e. $100 \%, 90 \%, 80 \%$, and $70 \%$ for $30-60$ s, then washed under tap water, rinsed with distilled water, and drained properly before staining with hematoxylin and eosin solution. The cell nuclei will be viable in blue color, erythrocytes in red color, and muscle and other connective tissue with cytoplasm in shades of pink.

\section{Statistical analysis}

All the findings are presented as mean \pm standard error of the mean $(\mathrm{n}=6)$, for serum biochemical parameter estimation, using one-way RM
ANOVA followed by Dunnett's post-test to compare all columns with the control group.

\section{RESULTS}

\section{Preliminary phytochemical screening}

The $\mathrm{CN}$ was screened for phytochemical estimation using various qualitative tests and ensured the presence of various phytochemicals such as glycosides, saponins, alkaloids, flavonoids, and terpenoids.

\section{Effect of $\mathrm{CN}$ on thyroid hormones}

Thyroxine $\left(\mathrm{T}_{4}\right.$ and $\left.\mathrm{FT}_{4}\right)$

Administration of the $\mathrm{CN}$ to healthy mice for 15 days, significantly soared $\mathrm{T}_{4}\left({ }^{* *} \mathrm{p}<0.01\right)$ and $\mathrm{FT}_{4}\left({ }^{*} \mathrm{p}<0.05\right)$ levels in NOR+CN 400 , whereas no deviation from normal levels, on the significant basis, was observed in NOR+CN 600 when compared to normal control, i.e., NOR+VEH (Figs. 1 and 2).

\section{Triiodothyronine $\left(T_{3}\right)$}

Administration of extract in healthy mice for 15 days significantly reduced the $T_{3}$ levels in both the groups, i.e. highly significant decline in NOR+CN $\left.400{ }^{* * *} \mathrm{p}<0.001\right)$ and significantly NOR+CN $600\left({ }^{* *} \mathrm{p}<0.01\right)$ as compared to NOR+VEH (Fig. 3).

\section{$T_{3} / T_{4}$ ratio}

The calculated $\mathrm{T}_{3} / \mathrm{T}_{4}$ ratio was found to be significantly less in NOR+CN $400\left(^{* *} \mathrm{p}<0.01\right)$, with respect to the normal control, whereas this ratio has been found to near normalcy in case of NOR+CN 600 (Fig. 4)

\section{Effect on TSH}

Administration of $\mathrm{CN}$ for 15 days in normal healthy female mice had not significantly altered the TSH levels in any of the test group with respect to normal control, thus depicting the subclinical changes at $\mathrm{T}_{3}$ levels (Fig. 5).

\section{Histology of thyroid gland}

The transverse section (T.S.) of thyroid gland of the normal group $(\mathrm{NOR}+\mathrm{VEH})$ showed the appearance of normal structural features such as follicular cells embedded in cuboidal epithelium ( $f$ ), colloidal appearance in follicles with slight variation in size $(c o)$, parafollicular cells or C-cells clustered in between the follicles $(p f)$, and fenestrated capillaries $(c a)$ with visible appearance of interlobular connective tissue (il) (Fig. 6a), whereas the thyroid gland in NOR+CN 600 appeared to have reduced follicular size $(f r)$ with undistinguished columnar epithelium (ue), the presence of C-cells ( $p f$ ), few capillaries $(c a)$, and large vacuole spaces ( $v a$ ) (Fig. 6b). The thyroid gland T.S. of group NOR+CN 600 depicted the bunch of follicles of variable size $(f \mathrm{v})$ with cuboidal epithelium and abundant follicular and cluster of C-cells ( $p f$ ) with the presence of colloid in different intensity $(c o)$ and blood capillaries (ca) (Fig. 6c)

\section{DISCUSSION}

Thyroxine $\left(\mathrm{T}_{4}\right)$ is the principle prohormone secreted from the thyroid gland. $\mathrm{T}_{4}$ thus produced is metabolically converted into its biologically active form $\mathrm{T}_{3}$, through the process of outer-ring monodeiodination by thioredoxin fold-containing selenoenzymes, known as iodothyronine deiodinases in cytoplasm and nucleus of target/extrathyroidal tissues mainly liver, kidneys, etc. $\mathrm{T}_{3}$ is secreted in small amount by the thyroid gland (13\%) and the majority is formed in peripheral tissues through Type I 5'idothyronine monodeiodinase (5'-DI) by peripheral monodeiodination to carry out pro-metabolic, pro-enzymatic, and lipolytic effects $[19,20]$. Suppression in levels of both $\mathrm{T}_{4}$ and $\mathrm{T}_{3}$ is seen in conditions of hypothyroidism or due to the effect of certain goitrogens like bamboo shoots as a food entity or bark of Ficus racemosa Linn. [21,22]. Any change in 5 'DI, i.e., inhibition is reflected by a decrease in $\mathrm{T}_{3}$ concentration and $\mathrm{T}_{3} / \mathrm{T}_{4}$ ratio, despite the increase in $\mathrm{T}_{4}$ concentration [23]. 


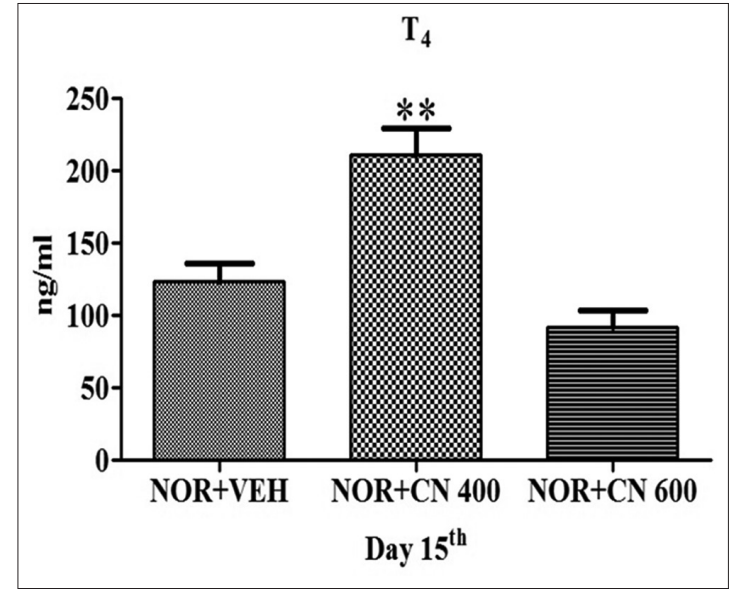

Fig. 1: Effect of Crataeva nurvala on total thyroxine levels (the values are presented as mean \pm standard error of the mean $(n=6)$, for serum biochemical parameter estimation, using one-way RM ANOVA followed by Dunnett's post-test to compare all columns with the control group, ${ }^{* *} \mathbf{p}<0.01$ )

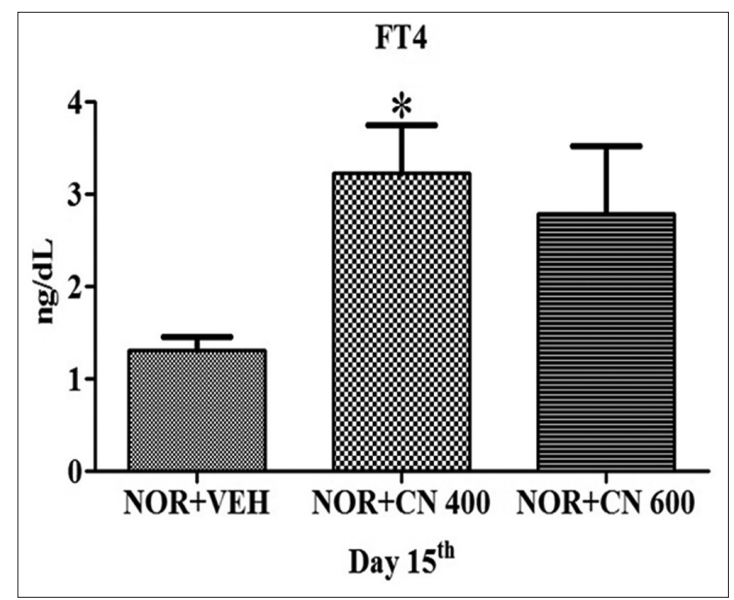

Fig. 2: Effect of Crataeva nurvala on free thyroxine levels (the values are presented as mean \pm standard error of the mean $(n=6)$, for serum biochemical parameter estimation, using one-way RM ANOVA followed by Dunnett's post-test to compare all columns with the control group, ${ }^{*} \mathbf{p}<0.05$ )

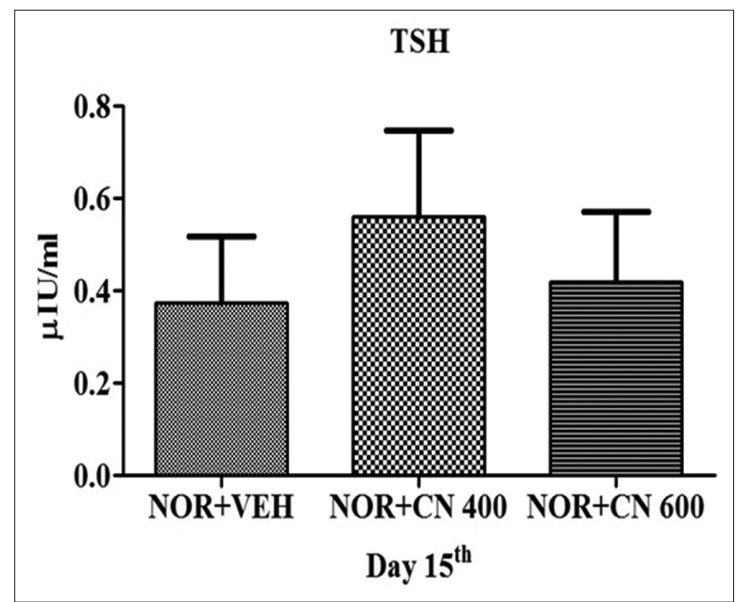

Fig. 5: Effect of Crataeva nurvala on thyroid-stimulating hormone (the values are presented as mean \pm standard error of the mean $(n=6)$, for serum biochemical parameter estimation, using oneway RM ANOVA followed by Dunnett's post-test to compare all columns with the control group)

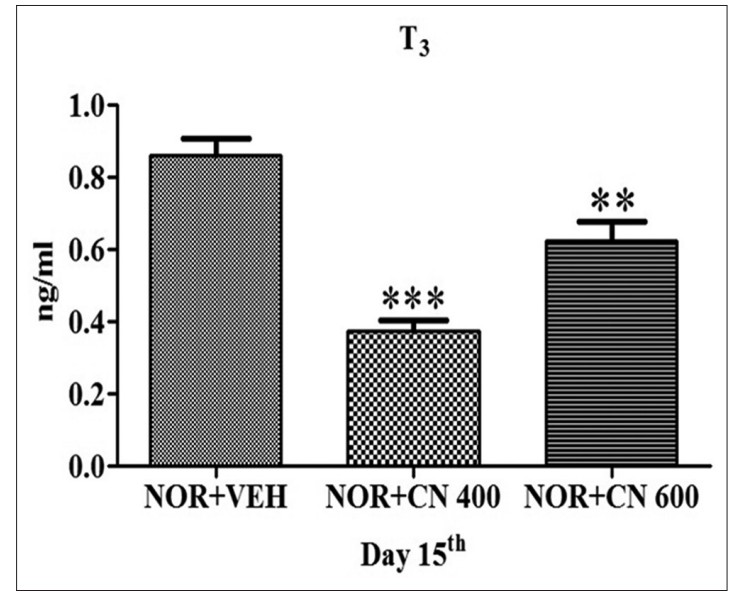

Fig. 3: Effect of Crataeva nurvala on triiodothyronine levels (the values are presented as mean \pm standard error of the mean $(n=6)$, for serum biochemical parameter estimation, using one-way RM ANOVA followed by Dunnett's post-test to compare all columns with the control group, ${ }^{* *} \mathbf{p}<0.01$ and ${ }^{* * *} \mathbf{p}<0.001$ )

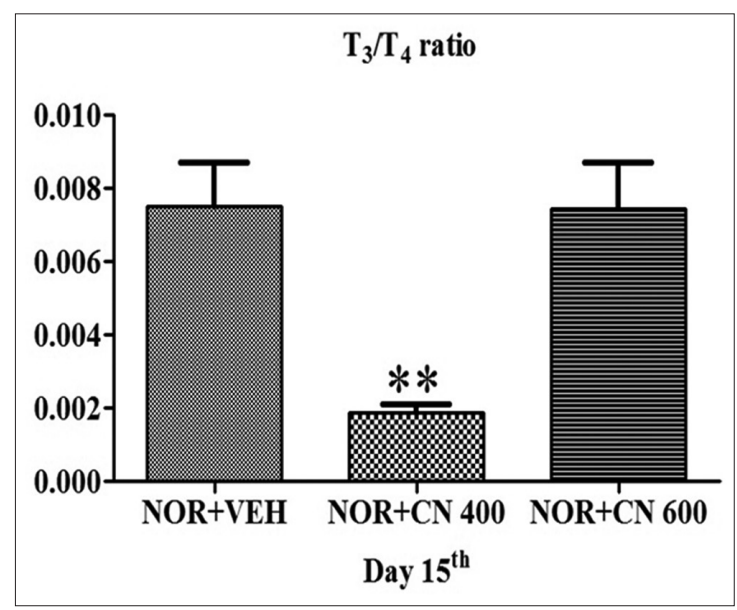

Fig. 4: Effect of Crataeva nurvala on $\mathrm{T}_{3} / \mathrm{T}_{4}$ ratio (the values are presented as mean \pm standard error of the mean $(n=6)$, for serum biochemical parameter estimation, using one-way RM ANOVA followed by Dunnett's post-test to compare all columns with the control group, ${ }^{* *}$ p $<0.01$ )

In this study, administration of the ethanolic extract of $\mathrm{CN}$ to healthy mice for 15 days significantly increased the levels of $\mathrm{T}_{4}\left({ }^{* *} \mathrm{p}<0.01\right)$ and $\mathrm{FT}_{4}\left({ }^{*} \mathrm{p}<0.05\right)$ in NOR+CN 400 , with a significant reduction in the $\mathrm{T}_{3}$ levels $\left({ }^{* *} \mathrm{p}<0.001\right.$ ) (Figs. 1-3). Whereas, in NOR+CN 600 , i.e. at the higher dose, the insignificant change was observed in thyroxine levels with significant $(* * \mathrm{p}<0.01)$ decrease is $\mathrm{T}_{3}$ levels as compared to normal control i.e. NOR+VEH (Figs. 1-3). However, no significant change was observed in TSH levels (Fig. 4). Hence, this extract might have some inhibitory effect on $5^{\prime} \mathrm{DI}$, thus affecting the peripheral deiodination, but this $5^{\prime} \mathrm{DI}$ inhibition is more marked with the lower dose as compared to the higher dose as $\mathrm{T}_{3} / \mathrm{T}_{4}$ ratio in NOR+CN 400 has significantly $\left({ }^{* *} \mathrm{p}<0.01\right)$ decreased as compared with NOR+CN 600 that retained the levels compared to normal group.

These results are in line with the study by Panda and Kar, 1999, done on root extract of Withania somnifera, given at the dose $1.4 \mathrm{~g} / \mathrm{kg}$ to female mice for about 20 days along with the additional parameter observed, i.e., hepatic glucose-6-phosphatase [24]. Tahiliani and Kar 1999 reported similar findings in their study on Moringa oleifera leaf extract, which showed approximately $30 \%$ reduction in $\mathrm{T}_{3}$, despite marked increased in $\mathrm{T}_{4}$ levels with antiperoxidative effects and is suggested to be used in hyperthyroidism conditions [25]. Aegle 


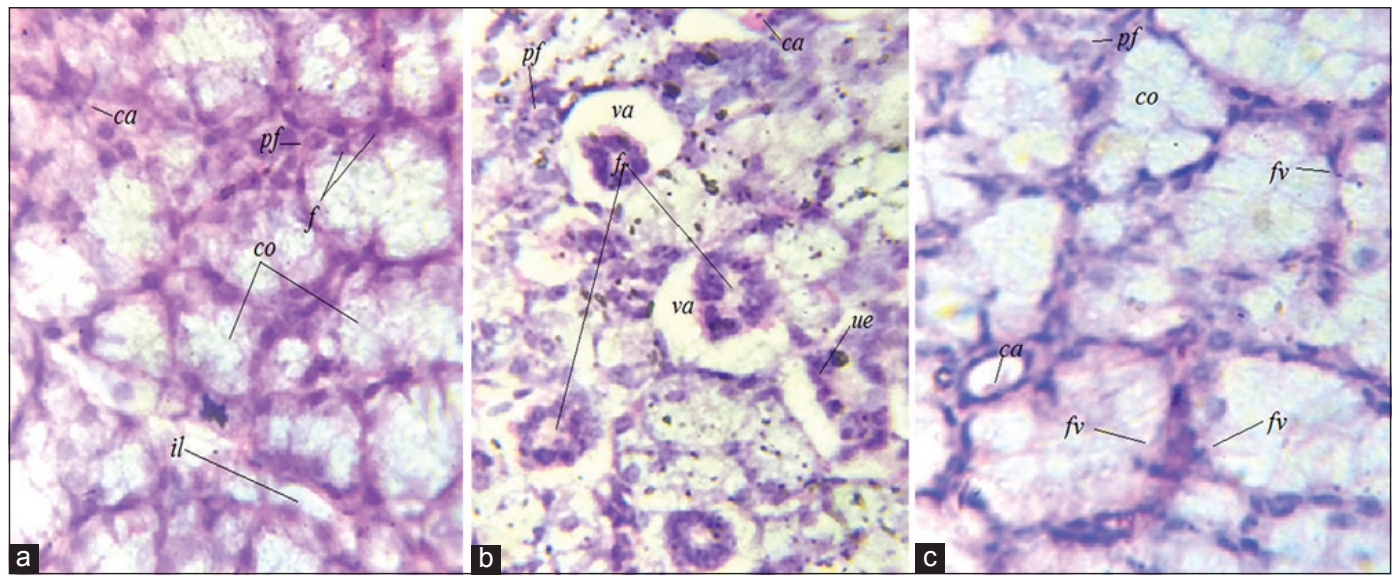

Fig. 6: Microscopic images of thyroid glands demonstrating the histological changes after the administration of the vehicle, Crataeva nurvala (CN) $400 \mathrm{mg} / \mathrm{kg}$ and $\mathrm{CN} 600 \mathrm{mg} / \mathrm{kg}$ for 15 days (a) control, NOR+VEH (b) NOR+CN 400 (c) NOR+CN 600; where pf-parafollicular cells or C-cells, f-follicles, co - colloid, $c a$ - capillaries, il - interlobular connective tissue, $f r$ - reduced follicular size, ue - undistinguished columnar epithelium, $v a$ - vacuoles, and $f v$ - variable size follicles. Hematoxylin and eosin staining $(\times 450)$

marmelos extract when studied by Kar et al. 2006, it was found that it could decrease $\mathrm{T}_{3}$ concentration by $62 \%$ depicting its possibility to be used in the regulation of thyroid disorder like hyperthyroidism [26]. Since our study also revealed that only $\mathrm{T}_{4}$ but not $\mathrm{T}_{3}$ was soared by lower dose, plant might stimulate the synthesis or the release of $\mathrm{T}_{4}$, directly at the glandular level but not through peripheral conversion of $\mathrm{T}_{4}$ to $\mathrm{T}_{3}$ which make it suitable for use in hyperthyroidism, while being higher dose remaining safe to be used for other ailments with respect to thyroid function.

Finding from previous studies using the ethanolic extract of CN in PTUinduced hypothyroidism revealed that $\mathrm{CN} 600 \mathrm{mg} / \mathrm{kg}$ has thyrotropic action as it significantly raised $\mathrm{T}_{4}$ levels $\left({ }^{* * *} \mathrm{p}<0.001\right)$ with a concomitant decrease in TSH $\left({ }^{*} \mathrm{p}<0.05\right)$ and associated hypercholesterolemia $\left.{ }^{* * *} \mathrm{p}<0.001\right)$. However, the lower dose proved to be less effective in correcting the disorder and seen to increase TSH. This may be attributed to more marked inhibition of 5'DIs by CN $400 \mathrm{mg} / \mathrm{kg}$, thus inhibiting the formation of $\mathrm{T}_{3}$ and rising the $\mathrm{TSH}$.

Structurally, the thyroid gland in rodents is similar to that of humans, except the difference in size of the follicles that are comparatively small and are surrounded by the cuboidal epithelium $[27,28]$. Petrova et al. 2014 demonstrated that the administration of l-thyroxine or availability of thyroid hormones is characterized by the presence of large size follicles, availability of more colloid, reduction in resorptive vacuoles with flattened follicular epithelium as it is evident from the images of normal (NOR+VEH), and the group administered with $\mathrm{CN} 600 \mathrm{mg} / \mathrm{kg}$, where no or less vacuolization was present and follicular size was large with flattened cuboidal epithelium, colloidal appearance in follicles, slightly variable in size, parafollicular cells, or C-cells in between the follicles, fenestrated capillaries with visible appearance of interlobular connective tissue [29]. Ali Rajab et al. 2015 demonstrated that the supranormal levels of thyroid hormones or conditions resembling hyperthyroidism distort the morphology of the gland characterized by distention of lumen of follicles, reduction in thyrocyte height, follicular remodeling (fusion), and thyrocyte death due to lack of trophic effect and cytoprotection offered by TSH [30]. NOR+CN 400 (Fig. 6b) depicted the hypotrophic follicles i.e., reduced in size and undistinguished epithelium, with presence of C-cells, capillaries, and vacuoles as compared to NOR+VEH group (Fig. 6 a).

NOR+CN 600 (Fig. 6c) depict the bunch of follicles with fused epithelium and abundant follicular and a cluster of C-cells with the presence of colloid in different intensity. However, blood capillaries and C-cells are visible with a number of follicles.
The thyroid gland comprises of acini or follicles that are spherical bodies that selectively absorb iodine in the form of iodide ions, $\mathrm{I}^{-}$from the blood circulation for the production of the thyroid hormones, and also for its adequate storage in thyroglobulin (Tg). $25 \%$ of the body's I-ions are in the thyroid gland. Follicles contain a region called the follicular lumen, containing colloid comprising of a protein, Tg that serves as the reservoir of materials for the thyroid hormone production and, to a lesser extent, also acts as a reservoir for already synthesized thyroid hormones. The follicles are lined by multiple cuboidal cells, whose size varies depending on age and locality $[31,32]$. The size of the follicles and the follicular lumen is found to be reduced in NOR+CN 400 group, thus indicating the depletion of colloid accompanied by vacuole formation, whereas normal follicular size with no vacuolization was seen in NOR+CN 600 (Fig. 6a and b). "C cells" or parafollicular cells which secrete calcitonin were found in abundance, scattered within the follicular cells and in the spaces between the spherical follicles in NOR+VEH and NOR+CN 600; however, they were poorly localized in NOR+CN 400. As the acini size has decreased in NOR+CN 400, the acinar epithelium appears more cuboidal as compared to NOR+VEH and NOR+CN 600, in which with the increased size of follicles and the epithelial lining becomes flatter or low cuboidal.

As per the findings of this study, $\mathrm{CN} 400 \mathrm{mg} / \mathrm{kg}$ was found to be beneficial to be used in hyperthyroidism, as evident from raised $\mathrm{T}_{4}$ and reduced $\mathrm{T}_{3}$ and $\mathrm{T}_{3} / \mathrm{T}_{4}$ ratio, whereas $\mathrm{CN} 600 \mathrm{mg} / \mathrm{kg}$ was able to maintain euthyroid state in per se or hypothyroid mice, compared to the normal group. For future studies, CN extract must be studied extensively for its effect on peripheral organs also such as determination of a additional parameter for thyroid function and glucose-6-phosphatase (G-6-Pase) activity in liver tissues as carbohydrate metabolism is also influenced by thyroid hormones and moreover the anti-peroxidative effects in relation to thyroid disorders [33]. However, before human therapy, further investigations are required such as the direct measurement of 5'DI using specific radioimmunoassay for more confirmation.

\section{CONCLUSION}

The ethanolic extract of $\mathrm{CN}$ is thyrotropic, stimulatory at glandular level but possesses the 5'DIs inhibitory activity in a dose-specific manner. Lower dose, i.e. CN $400 \mathrm{mg} / \mathrm{kg}$ is suitable to be used in hyperthyroidism, whereas higher dose, i.e. CN $600 \mathrm{mg} / \mathrm{kg}$ is found to be effective in hypothyroidism, in maintaining euthyroid levels and in retaining normal histoarchitecture of the thyroid gland as evident from preclinical studies. 


\section{ACKNOWLEDGMENTS}

This project was a part of M. Pharmacy (Pharmacology) research protocol. The support and guidance of all teaching, non-teaching, and technical staff of the Department of Pharmacology, CT Institute of Pharmaceutical Sciences, School of Pharmaceutical Sciences, Lovely Professional University, for providing the basic facilities, resources, and in the completion of the study and communication of research outcomes is highly appreciable.

\section{AUTHOR'S CONTRIBUTIONS}

All the authors have significantly contributed to the concept, design, definition of intellectual content, literature research, the conduct of the study, manuscript editing, preparation, and review.

\section{CONFLICTS OF INTEREST STATEMENT}

The authors mentioned in this paper do not have any personal or financial relationship with any other person or organization that can influence the content of the paper.

\section{REFERENCES}

1. Bopana N, Saxena S. Crataeva nurvala: A valuable medicinal plant. J Herbs Spices Med Plants 2008;14 1 Supp 2:107-27.

2. Khattar V, Wal A. Utilities of Crataeva nurvala. Int J Pharm Pharm Sci 2012;4:21-6.

3. Kamath R, Shetty D, Bhat P, Shabaraya AR, Hegde K. Evaluation of antibacterial and anthelmi tic activity of root extract of Crataeva nurvala. Pharmacologyonline 2011;1:671-2.

4. Chidambaram K, Albert J, Karpagam K. Antipyretic activity of Crateva magna bark on tab-vaccine induced pyrexia. Int J Pharm Sci Res 2011;2:856-9.

5. Shelkea TT, Bhaskar VH, Adkara PP, Jhaa U, Oswala RJ. Nephroprotective activity of ethanolic extract of stem barks of Crataeva nurvula Buch Hum. Int J Pharm Sci Res 2011;2:2712-7.

6. Pattanaik SO, Si SC, Nayak SS. Evaluation of free radical scavenging activity, wound healing activity and estimation of phenolic, flavonoid and proanthocyanidin contents of the plant "Crateva magna". Asian J Pharm Clin Res 2012;5:168-71.

7. Bulbul L, Choudhuri MS. Effect of Asmarihara kasaya curna (ASM)-an ayurvedic formulation on lipid profile after chronic administration. Int $\mathrm{J}$ Basic Med Sci Pharm 2012;2:83-7.

8. Gupta SK, Baghel MS, Bhuyan C, Ravishankar B, Ashok BK, Patil PD. Evaluation of anti-urolithiatic activity of pashanabhedadi ghrita against experimentally induced renal calculi in rats. Ayu 2012;33:429-34.

9. Akila B, Manickavasakam K. Anti-inflammatory and ant nociceptive activity of two Siddha formulations in combination. Int J Pharm Sci Res 2013;4:856-61.

10. Chakraborthy S, Karamakar D, Kolhapure SA. Evaluation of the efficacy and safety of Himplasia in BPH: A randomised, double-blind, placebo-controlled, phase III clinical trial. Med Update 2004;12:39-48.

11. Barwal A, Kumari S, Verma SK, Goyal PK, Sharma I, Sharma S, et al. Evaluation of herbal formulation neeri (NS-RF) for protective effect against heavy metal induced nephrotoxicity in rats. Indo Am J Pharm Sci 2015;5:2790-8.

12. Kaur A, Khurana N, Verma SK. Potential thyrotropic and antihypercholesteronemic activity exhibited by ethanolic extract of Crataeva nurvala bark. J Appl Pharm Sci 2017;7:69-73.

13. Hussain M, Bakhsh H, Aziz A, Majeed A, Khan IA, Mujeeb A, et al. Comparative in vitro study of antimicrobial activities of flower and whole plant of Jasminum officinale against some human pathogenic microbes. J Pharm Altern Med 2013;2:33-43.

14. Sikarwar MS, Patil MB. Antihyperlipidemic activity of Crataeva nurvula stem barks extracts. Indian J Pharm Educ Res 2012;46:378-82.

15. Bhattacharjee A, Shashidhara SC, Saha S. Neuroprotective activity of Crataeva nurvula Buch-Ham stem bark against scopolamine - Induced cognitive impairment via antioxidative activites in rats. Am J Ethnomed 2014;1:371-83.

16. Panda A, Rath S, Pradhan D, Mahanty A, Gupta BK, Bala NN. Hepatoprotective activity of leaves of Crataeva magna (Lour.) DC. In different types of hepatotoxic rat models. Indo Am J Pharm Res 2014;4:125-31.

17. Shelkea TT, Bhaskarb VH, Adkara PP, Jhaa U, Oswala RJ. Nephroprotective activity of ethanolic extract of stem barks of Crataeva nurvula Buch. Ham. Int J Pharm Sci Res 2011;2:2712-7.

18. Sayaki H, Azure B. Counterstain in the immunohistochemical evaluation of heavily pigmented nevomelanocytic lesion. Appl Immunohistochem 1955;3:268-71.

19. Bianco AC, Salvatore D, Gereben B, Berry MJ, Larsen PR. Biochemistry, cellular and molecular biology, and physiological roles of the iodothyronine selenodeiodinases. Endocr Rev 2002;23:38-89.

20. Greenspan FS. The thyroid gland. In: Greenspan FS, Baxter JD, editors. Basic and Clinical Endocrinology. Englewood Cliffs, New Jersy: Prentice Hall International Inc.; 1994. p. 160-226.

21. Sarkar D, Chakraborty A, Bhattacharya C, Singh LH, Chandra AK. Exploration of goitrogenic/antithyroidal potentiality of bamboo-shoots in relation to thiourea. Int J Pharm Pharm Sci 2017;9:7-12.

22. Azharuddin M, Atif M, Ahmed MI, Bakhtiary SA, Ibrahim M. Evaluation of anti-thyroid activity of Ficus racemosa Linn bark in male rats. Int J Pharm Pharm Sci 2015;7:118-22.

23. Visser TJ, Vander dose-tobe I, Hennemann G. Conversion of thyroxine into triiodothyronine by rat liver homogenate. Biochem J 1978;150:489-93

24. Panda S, Kar A. Withania somnifera and Bauhinia purpurea in the regulation of circulating thyroid hormone concentrations in female mice. J Ethnopharmacol 1999;67:233-9.

25. Tahiliani P, Kar A. Role of Moringa oleifera leaf extract in the regulation of thyroid hormone status in adult male and female rats. Pharmacol Res 2000;41:319-23.

26. Panda S, Kar A. Evaluation of the antithyroid, antioxidative and antihyperglycemic activity of scopoletin from Aegle marmelos leaves in hyperthyroid rats. Phytother Res 2006;20:1103-5.

27. Choksi NY, Jahnke GD, Hilaire CS, Shelby M. Role of thyroid hormones in human and laboratory animal reproduction health. Birth Defects Res (Part B) 2003;68:479-91.

28. U.S. EPA. Assessment of Thyroid Follicular Cell Tumors. Washington, DC: EPA 1998.

29. Petrova I, Mitevska E, Gerasimovska Z, Milenkova L, Kostovska N. Histological structure of the thyroid gland in apolipoprotein E deficient female mice after levothyroxine application. Contributions Sec Med Sci 2014;35:135-40.

30. Rajab NM, Ukropina M, Cakic-Milosevic, M. Histological and ultrastructural alterations of rat thyroid gland after short-term treatment with high doses of thyroid hormones. Saudi J Biol Sci 2017;24:1117-25.

31. Rice CO. Histologic structure of the normal thyroid gland: Variations and their significance in the interpretation of pathologic conditions of the thyroid gland. Arch Surg 1938;36:96-110.

32. Fawcett D, Jensh R. Bloom and Fawcett's Concise Histology. New York: Arnold Publishers; 2002.

33. Muller MJ, Acheson KJ, Jequier E, Burger AG. Effects of thyroid hormones on oxidative and nonoxidative glucose metabolism in mice. Am J Physiol 1988; 18:146-52. 